2015-04-13

\title{
Planning robust policing futures: modelling using multimethodology
}

Moizer, Jonathan

http://hdl.handle.net/10026.1/3385

10.1108/IMDS-11-2014-0336

Industrial Management and Data Systems

Emerald

All content in PEARL is protected by copyright law. Author manuscripts are made available in accordance with publisher policies. Please cite only the published version using the details provided on the item record or document. In the absence of an open licence (e.g. Creative Commons), permissions for further reuse of content should be sought from the publisher or author. 


\title{
Planning Robust Policing Futures: Modelling using Multimethodology
}

\author{
Jonathan Moizer (jmoizer@plymouth.ac.uk), David Carter \\ (david.carter@plymouth.ac.uk) and Shaofeng Liu \\ (shaofeng.liu@plymouth.ac.uk) \\ Faculty of Business, Plymouth University, Plymouth, United Kingdom
}

\begin{abstract}
Purpose - The resourcing of policing activity is characterised by a level of complexity, particularly where evaluating alternative policy options is concerned. In this paper, a case study using multimethodological modelling to compare alterative policy choice in a group context is outlined with respect to response-patrol officer deployment within a UK police force.
\end{abstract}

Design/methodology/approach - The application of a three phase modelling process is illustrated where scenario planning is used to generate the scope of the system elements to be modelled. This is followed by causal mapping to identify the barriers to improving officer resourcing, and system dynamics modelling is used to simulate the impacts of a range of policy options within this policing function. A group model building approach was applied throughout the modelling phases with an expert group to negotiate a shared view of the structure and dynamics of the resourcing policy challenges.

Findings - A fully validated system dynamics model emerged from the multi-phase modelling process which allowed a series of alternative future policy scenarios to be explored and evaluated. Useful policy insights were generated by the system dynamics simulation model which suggested more efficient rules for resource allocation in the police force's response-patrol officer function.

Originality/value - The insights from this case study demonstrates that multi-phase modelling has potential application in policy exploration across a range of emergency service providers whose actions are governed by both variable demand and constrained supply of resource.

Keywords Group model building, Multimethodology, Scenario planning, Causal map, System dynamics, Simulation, Modelling, Police, Patrol

Paper type Research paper 


\section{Introduction}

Systems thinking is concerned with the interrelationship between constituent parts and a functioning whole (Trochim et al, 2006). System science as a discipline has both breadth and depth, but specifically within this, systems modelling can be used to increase understanding of complex systems through the exploration of causeeffect and decision making, often where feedbacks exist. Scenario thinking can be used to identify the key driving forces for change which assist model builders in determining the system scope to be modelled.

Complex decision making in the public sector organisations is widespread within large government departments who have to manage an array of often competing stakeholder expectations when deciding between alternatives. Cross-sectional Operation Research techniques have been developed to support detailed decision making but without always being able to consider the longitudinal implications for following a particular course of action. Dynamically complex issues inherent to public sector organisations can be addressed by understanding the underlying systemic structure and resulting behaviours (Sterman, 2001). Typically, where cause and effect are separated by time and distance, making decisions can be frustrated by unintended consequences that need studying before finalising the decision. A number of system modelling techniques exist but system dynamics is a quantified approach that is particularly suited to modelling complex management problems that vary with time, and are characterised by resource accumulations and flows, information links, feedback mechanisms, delays and non-linearities, all of which are inherent to most managed systems. The approach was first developed by Forrester (1961) to examine supply chain oscillations. Since then system dynamics has evolved both methodologically and in application.

Policing a community is characterised by diverse and complex decision making processes, from real time actions on the front line through to more strategic decisions being made by the Chief Officer Group under Home Office ${ }^{1}$ direction. Police operations always involve the public, whether keeping them safe from harm or protecting their property. Invariably the first on the scene of an incident are the patrol officers who represent a significant constituent of any policing system. Police authorities continue to develop police patrol strategies and operations that provide safety in a resource efficient and effective way (Zhang and Brown, 2013). Often this is achieved through taking a more business-like approach through the application of New Pubic Management principles (Barton and Barton, 2011).

A tension exists between the need for patrol officers to resolve pressing incidents and the requirement to develop and maintain extensive policing skills and capabilities. Longer term allocation of resource to police patrol officer recruitment, training and development is essential if the needs of the community are to be met. The disparity in timescales between almost instantaneous demand for police assistance and a long lead time in developing sufficient officer capacity and capability can lead to significant dynamic imbalances in the system. Such long delays between actions and their consequences make effective experiential learning extremely difficult. By the time policies and decisions are developed, their impact measured, and policy adjustments made, more permanent unintended consequences can be rendered (Ghaffarzadegan et al, 2011). To avoid this, simulation models can be built which inform understanding of the impact of decision making within complex and chaotic environments before actual changes are made. 
This is where insights on effective resource development and allocation can guide policy and decision making. Simulation models can help police forces test out key assumptions concerning strategic resourcing in a risk free way to help establish viable futures for patrol officer policing operations. Dealing with systemic complexity and associated risk under conditions of uncertainty requires organisations to view their world through multiple perspectives and accommodate a range of alternative views for the future as scenarios or descriptions of plausible futures (Lindgren and Bandhold, 2003).

Although a number of research papers report on the use of spatial modelling (Curtin et al, 2010; Zhang and Brown, 2013; Li et al, 2011; Barbosa and Petty, 2014) and discrete event modelling of operational level resource decisions in police patrol systems (Brooks et al, 2011; Srinivasan et al, 2013) there does not appear to be any research published on simulation modelling of more strategic and policy orientated patrol officer resourcing. This paper aims to demonstrate how group based multimethodological modelling can been used to support the development of a robust policy oriented system dynamics model for patrol officer resource evaluation. The multimethodology presented comprises of three phases:

1. scoping alternative future states using scenario based cross-impact analysis;

2. capturing representations of existing policy and control interactions through causal mapping of different scenarios; and

3. translating causal structures into viable alternative policy decisions using system dynamics modelling.

The paper is organised as follows. Firstly, an exposition of the multimethodology literature, followed by a review of the group model building methodology. Lastly, the police modelling case study is described along with how multimethodological modelling was applied. The use of multimethodology within a group model building setting is then discussed. Finally, within the conclusions, the utility and effectiveness of the case modelling intervention and lessons for organising modelling processes is reflected upon.

\section{Multimethodology Modelling}

In many instances, one modelling method can be sufficient to address real-world issues. A wide range of softer, qualitative operational research methods have been developed over the last fifty years to compliment initial approaches that are based solely on quantitative mathematics. As the number of modelling methods, both hard and soft, has grown, so has the opportunity to combine more than one method together. Where the issue is characterised by higher levels of complexity, it may be necessary to mix several modelling approaches to address it. Combining whole or part methods together for resolving a particular issue is known as multimethodology (Mingers and Brocklesby, 1997; Munro and Mingers, 2002). Multimethodology has been developed over several decades with a large number of publications produced (see review by Howick and Ackermann, 2011). It has been typically based on combining softer problem structuring techniques (Mingers, 2000), but more recently there has been an increased mix of approaches where softer methods have been applied alongside more traditional, harder operational research techniques such as mathematical analysis (Ferreira, 2012) and data mining (Brown et al, 2006). An earlier survey conducted by Munro and Mingers (2002) of operational research 
specialists identifies this emerging pattern. The study was primarily conducted in the UK to assess the use of multimethodology amongst academics and operational research practitioners. It established that two or three methods employed in combination is common practice. It revealed that equal combinations of hard, soft and mixed approaches are used within multimethodology, with certain techniques often applied in combination. For instance, Delphi and scenario planning for exploring futures; rich picture development emerging from Viable Systems Model and Soft System Methodology; plus using cognitive mapping as a front-end structuring method for the development of system dynamics models.

Multimethodology can be used to address multi-dimensional issues above and beyond what is possible from the application of a single method. This is particularly the case in group based situations where a rich picture of contributor views is required to be produced (Mingers and Brocklesby, 1997). Due to the complexity of many real world issues, alternative methods can be applied to tackle different aspects of the situation, thus enabling a multimethodology selection to focus on that full richness that is present in the real world. A complex modelling intervention may not only comprise a single event but may stretch over a number of stages where relevant methods are combined to yield superior insights and predictions. Whilst the benefits of multimethodology are easily recognised, there are some potential difficulties, not least, encouraging participants to switch their perspective between techniques and the difficulty of understanding how to competently apply several methods in one intervention (Kotiadis and Mingers, 2006).

System dynamics modelling is a popular approach to examining many real world issues in concert with other methods, typically where softer problem structuring techniques are used to formulate thinking, followed by the construction and parameterisation of a simulation model. Ackermann et al (2011) has used Journey Making $^{[2]}$ (a causal mapping technique) combined with system dynamics modelling as a multimethodology to allow participants to examine complex issues in stakeholder based policy making workshops (Ackermann et al, 2011). Others have combined system dynamic models with complimentary operational research methods. For instance, Santos et al (2008) consider health service provision using one such combination of methods to understand the performance scores associated with different policy interventions in a hospital department. Based on combining system dynamics and multi-criteria decision making they predict performance scores for an oncology unit based on alternative resourcing options. System dynamics has been combined with other operational research/problem structuring techniques to model a range of issues. Howick and Eden (2011) describe a combination of using Journey Making with quantitative system dynamics to support strategy development in a large UK police force.

On the harder modelling front, through combining Unified Modelling Language and system dynamics modelling, Bérard et al (2011) report another healthcare case study of using a simulation model to evaluate IT support for clinical trials. Wang and Moon (2012) also use hybrid modelling where agent-based modelling and system dynamics are used to examine alternative strategies for the deployment of innovations in organisations. Ip et al (2011) propose an integrated approach to measuring supply chain performance using system dynamics and autoregressive integrated moving average models using a case study of a semiconductor equipment manufacturer. Another illustration of hybrid modelling is provided by Jovanoski et al (2013) who use system dynamics modelling to examine strategic issues and discrete 
event simulation to evaluate decisions in production management systems. Whether described as multimethodology or hybrid modelling, system dynamics in combination with other softer or harder modelling techniques has shown to result in better models being built than in using system dynamics alone.

\section{Group Model Building}

The concept of facilitated modelling has been applied to different hard and soft operational research techniques (Franco and Montibeller, 2010) with examples including Group Model Building (GMB) methodology for system dynamics modelling. All such model building facilitation methods encourage problem owners to take part in model development and subsequently adopt future outcomes predicted by the model through clear and transparent (white-box) construction processes (Andersen and Richardson, 1997). This is in direct contrast to earlier model building approaches where often the focus has been on the construction of grey-box models ${ }^{[3]}$ where the client has some limited understanding of the link between model structure and behaviour.

Simulation models built with expert contributions offer particular utility when verifying structure and validating numerical parameters. Also known as collaborative modelling (Van den Belt, 2004), GMB with system dynamics can offer insight on messy and complex issues embedded within high-order systems where multiple cause and effect are separated by time and distance. This approach creates system dynamics models designed to achieve specific goals by means of rational description and reasoning (Hoppenbrouwers and Rouwette, 2012). GMB amongst stakeholders supports strategic decision making through generating information about an issue under consideration in a participatory way. This consensus-based approach can help to create ownership of the issue and help solidify management commitment to actual implementation of the recommendations that the model supports (Akkermans and Vennix, 1997). In addition, GMB supports the development of a shared language amongst participants, allowing them to better understand each other (Rouwette et al, 2002). GMB also seeks to overcome the heuristics inherent to "traditional" decision making through integrating and structuring available information (Rouwette, 2011). It is a modelling process that is able to capture judgemental data and incorporate this into quantitative model formulations (Luna-Reyes and Andersen, 2003) via the use of scripts. These scripts enable different types of information to be captured and represented in a modelling form by specifying in advance the activities required to produce models (Richardson and Andersen, 1995; Vennix, 1996, 1999).

GMB sessions are organised through facilitators who prepare scripts to help participants contribute effectively to each stage of the model building process. In a typical GMB exercise, participants develop one or more system dynamics models during structured and facilitated workshops where knowledge is elicited from stakeholders (Bérard, 2010). Visual facilitation techniques such as causal mapping and stock-flow diagramming are used in combination in the facilitated workshops (Akkermans and Vennix, 1997; Ackermann et al, 2010). Good facilitation can allow the participants mental models to be shared (Vennix et al, 1996).

According to Vennix (1999), messy issues often render different viewpoints amongst participants in a model building process, requiring a GMB approach to be employed to gain group acceptance. When combined with multimethodologies, 
GMB can generate a level of negotiated consensus on the issue(s) of interest and increase the information processing capability within the group. In addition, providing feedback in a GMB setting can serve to clarify fuzzy ideas through recounting stories that result in dynamic insights obtained for the whole group (LunaReyes et al, 2006). Scripting techniques provide a valuable route map to allow efficient use of time used for model building. Even so, typical system dynamics interventions often take days to complete with even longer time lapses between workshops. Within organisations, top management are often involved with initiating a GMB process to understand how to address complex managerial and policy issues where their support is essential (Andersen et al, 1997). GMB teams are formed with key actors that management select. Direct management involvement may continue by contributing within the group or can cease at this early point, relying instead upon progress reports to reduce their time commitment. There is the danger though that by reducing involvement in this manner, managers may not benefit from the communications within the group, thus potentially weakening their commitment to the modelling outcomes.

A range of issues have been examined using GMB with system dynamics modelling. Ecology has been a popular application (Stave, 2002; Château et al, 2012) especially where public engagement is at stake. Messy public sector topics addressed using GMB principles include national shipping policy (Vennix, 1995), emergency services management (Luna-Reyes et al, 2004), criminal justice (GilGarcia and Pardo, 2006) and, policing themes (Newsome, 2008; Howick and Eden, 2011).

Rouwette et al. (2011) recognise the contribution modelling can make in translating messy issues into clearer problems, especially where participants have a rich stock of prior knowledge on the issues of concern. Stories can be used to translate experience into examples that can be built into a model. The importance of bringing the participants' different experiences and perspectives into the GMB process cannot be underestimated, particularly where participants may hold unique knowledge. Policing offers a fertile storytelling environment where participants in GMB produce a rich stock of stories about multiple aspects of policing policy.

\section{Policing Case Study}

Devon and Cornwall are two counties in southwest England served by a single police service, Devon and Cornwall Police (DCP). Its response patrol-officer function supports the majority of urgent requests for public assistance. DCP had decided to increase the overall police officer headcount from 3,200 to 3,500 in response to growing demands on their services. As the entry point into DCP, the response-patrol officer function was having to accommodate an increased number of recruits, while still losing a high number of experiences officers to tenured ${ }^{[4]}$ posts. This had dynamic implications for retention of experience within the response-patrol officer (RPO) function requiring evaluation of different policy responses to this issue.

\subsection{The current response-patrol officer system}

A supply-demand relationship exists between the provision of officers to meet the demands for assistance. Demand for officer response is categorised according to priority (incidents require immediate, prompt or routine attention). The flow of demand for officer assistance is largely instantaneous. This contrasts to the flow of 
trained officers into the patrol pool where lead times of two years between recruitment and entering the pool exist. Slow officer supply and fast demand for officer response can lead to a supply-demand mismatch if forward planning for provision of officer headcount is inadequate.

This phenomenon, coupled with changes in government policy, generate uncertainty and introduce complexity into longer term planning. In such circumstances, a resource strategy that considers only one future may not be appropriate. DCP were seeking to explore alternative policy futures for allocating RPO resource to meet public demand. Simulation modelling was an approach that could provide policy evaluation into the future state of the RPO system. Home Office initiatives aimed at improving police services included Workforce Modernisation (developing officer resourcing processes), Operation Quest (augmenting business processes) and The Policing Pledge (increasing customer satisfaction and public confidence), and it was therefore important to incorporate elements of these frameworks into any simulation modelling for exploring their impact on the effectiveness of the RPO function.

\subsection{Applying the multimethodology to the case study}

The methodological approach provided participants with the necessary perspectives to inform robust policy making. Arriving at a fully validated model to support response-patrol officer (RPO) allocation would require the contribution of system actors with relevant expertise and know-how throughout the methodological phases. Six experts participated, comprising mid-ranking police officers (sergeants and inspectors involved in front-line and training roles) and equivalent civilian managers who were able to offer a wealth of knowledge about how RPO demand and supply operate in practice. Participant selection was based on relevant knowledge, access to information and ability to communicate model outcomes and practical implementations. As trusted 'middle-out' members of DCP, this group could help to frame issues, interpret any model inputs and disseminate alternative policy outcomes both vertically (throughout management hierarchy) and laterally (across functional boundaries).

Figure 1 represents its three phases. It began with the client group identifying viable alternative futures through scoping the boundaries of the investigation (Phase One). At this point, discrete sequences of interacting factors were recognised by the group reflecting four possible broad futures of RPO resourcing. Contributors then structured a set of viable scenarios from these futures using causal mapping to identify the influences on system behaviour that need to be taken into account when looking to establish parameters, decision rules and feedback mechanisms (Phase Two). This provided greater definition of the four identified scenarios by making these specific to the DCP situation. Detailed policy decision options were next analysed using a system dynamics model, whose structure and parameters were configured for each future state. The simulation was run and the outputs of each policy test were comparatively evaluated (Phase Three). The simulation model provided a rational mathematical description of possible policy journeys from the current to future states. This three phase methodology can deliver a reliable and reproducible approach for developing wider views of the future against which policing strategies, policies and practice can be tested and evaluated. 
In the group engagement, it was important to scope out the final system dynamics model boundaries as early as possible to engage the client in understanding what qualitative futures may or may not be possible before taking them through latter quantification phases. By this means we hoped to be able to generate a set of robust alternatives policy outcomes that the group could own and share with others to support strategic thinking.

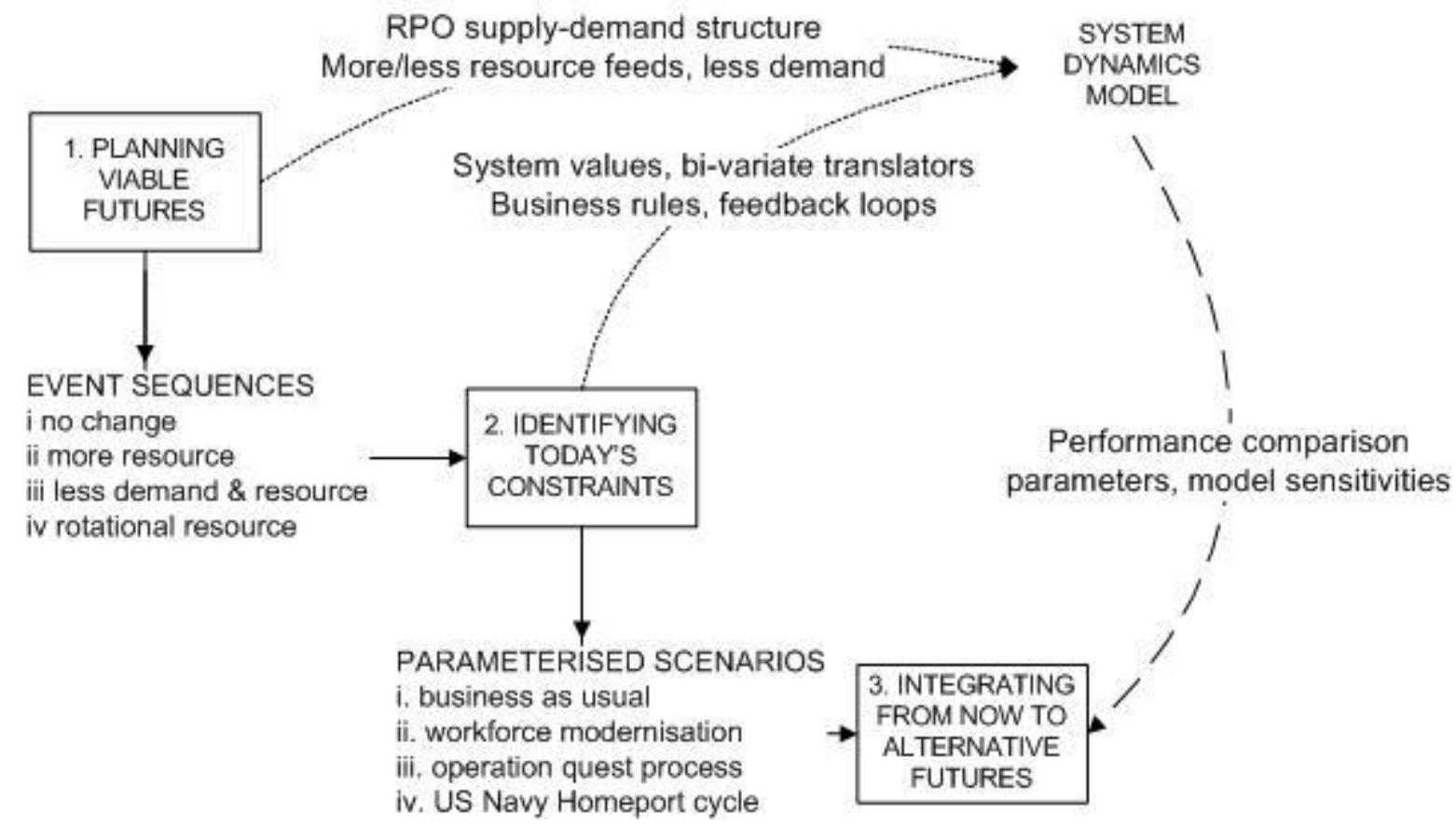

Figure 1. The Three Phase Methodology

\subsection{The group model building process}

In addition to the six participants involved in the group model building, an additional DCP colleague held a dual role as both GMB facilitator and also offline modeller. His role was to elicit knowledge from the group and reflect these constructs within the models, reporting back on progress to the group as the build proceeded. Shared constructs were mapped out on whiteboards and acetates, and audio recordings of conversations were made to help the modeller to refine model structures and parameters in-between workshops. From within the group, a police project manager acted as gatekeeper to help to confirm group views with the facilitator and vice versa.

The group met across three GMB workshops, each separated by one week intervals. This enabled feedback from workshops to be provided ahead of the next one. At the start of each workshop, the sequence and timing of activities was outlined by the facilitator. These activities were pre-assembled in the form of scripts which reflected each elicitation procedure for the particular workshop. Scripts allowed each workshop to move towards realising objectives within their allocated time and generate useful group insights. 


\subsubsection{Phase One: Planning viable futures}

Phase One involved group contributions within a futures planning workshop to scope the potential boundaries and broad content for structuring a system dynamics model of the RPO resourcing issue. The approach considered interactions between external environmental factors over time. This formed the basis of a credible description of potential future states and enabled the internal requirements of the RPO system and its resourcing to be understood.

A scripted process was set in place to help the GMB participants identify the broad model components that would need to be used to support the simulation of alternative policy futures. This comprised of using a PESTEL ${ }^{[5]}$ framework to elicit participant views on key future external variables and their level of impact on RPO resourcing. A cross-impact matrix was assembled using the PESTEL categories to frame the direct influences between individual factors (i.e. factors residing within each PESTEL category) defining the system. The cross-impact matrix axes of the matrix represent drivers or cause (vertical axis) and interacting impact or effect (horizontal axis). For each of the intersecting factors, input (cause) rows were compared against output (effect) columns to determine the strength of influence and dependence between them. For most cells a no cause-effect relationship was identified (a zero score assigned), but in cases where participants identified a relationship, the strength of causality was gauged on a scale of low (1), medium (2) or high (3). The polarity of each relationship (positive or negative gradient between cause and effect) was assigned by the group to the intersect using a plus or minus symbol. Each identified intersection represents a significant potential event for the system. Figure 2 represents an example sequence of three related events mapped onto the matrix. The resulting cross-impact matrix chart allowed the journey to be mapped from driver to resulting impact against the PESTEL axes. The group described the logical order of these sets of cause-effect events. The journey between events was plotted as a trajectory on the matrix between key points in time associated with each viable future. This helped participants to sketch-out specific alternative futures.

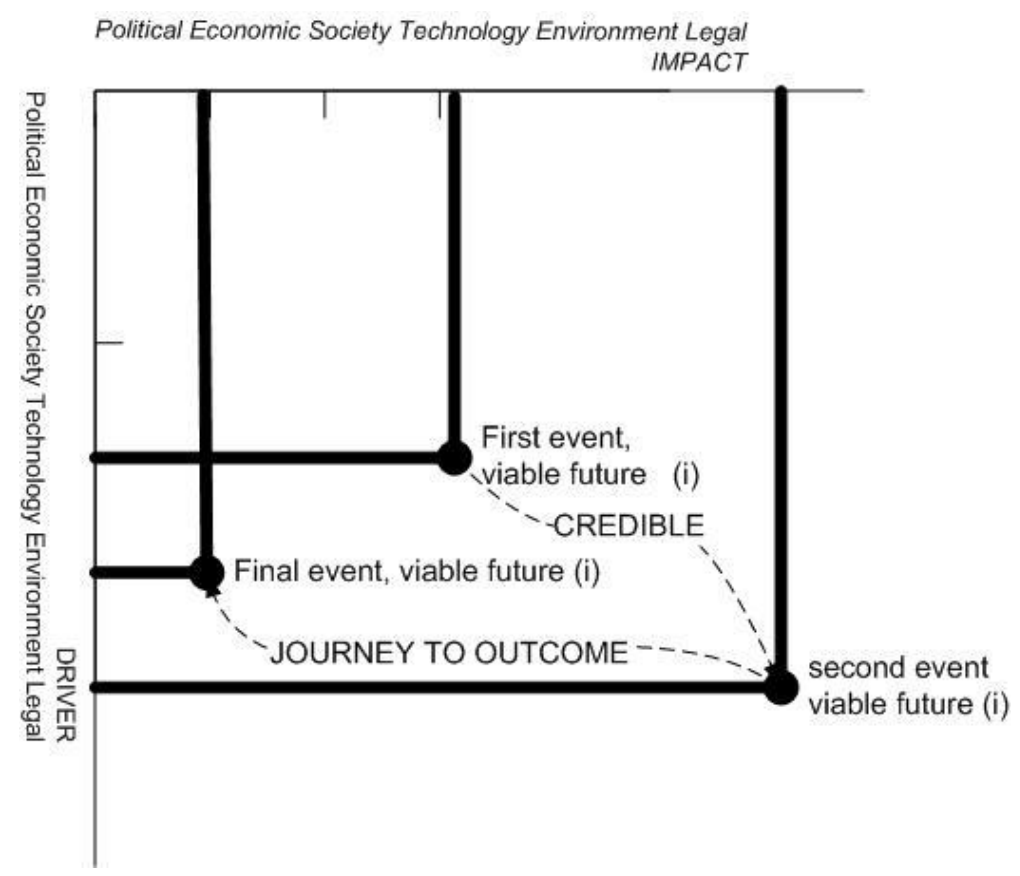

Figure 2. Example Cross-Impact Matrix Chart 
It was notable that the most significant number of cause and effect interactions occurred between factors under the Political and Legal categories. Political and legal Home Office directives need to be translated into actions at the individual police force level which heavily influenced the identification of system boundaries. Within the system boundaries, participants considered several alternative future states based on demands from external factors including:

a. improving the response-patrol officer (RPO) headcount to allow efficient incident resolution;

b. better training into the RPO function, process improvement potentially leading to faster incident resolution;

c. combination of $a$. and $b$;

d. none of the above.

In response to such challenges the following four policing response futures were identified by the participants for developing into modelling scenarios:

No Change Future (i) - No new measures to address changes in the external environment. Let existing system trends roll forward with RPO headcount and knowledge base continuing to change.

More Resources Future (ii) - Redeploy extra officers from tenured roles to meet RPO front-line response requirements. Backfill tenured vacancies with administrative resource. RPO resource will be boosted with an injection of new officer numbers.

Less Demand and Resource Future (iii) - Improve RPO utilisation through process improvement, where the scope of RPO activity is reduced along with the officer headcount. Less critical incidents can be dealt with by other policing functions allowing the RPO to deal with more serious incidents.

Rotational Resource Future (iv) - Setting up a rotational flow of officers to ensure that skill levels are maintained when dealing with the general public on the front-line. This necessitates a regular return of tenured officers into the RPO to maintain sufficient headcount and officer experience.

From Phase One, both system structure and outlying content were established for the alternative RPO resourcing futures. This increased group understanding of this resourcing issue and clarified the process for overcoming the current barriers to realising alternative and viable futures.

\subsubsection{Phase Two: Identifying today's constraints}

Following on from the scenario planning ${ }^{[6]}$ workshop at Phase One, a Group Model Building (GMB) viable futures workshop was set up to agree where potential barriers to future RPO resourcing might exist within the current system and how those could be overcome. This workshop was designed to provide essential clarity around current barriers towards alternative future destinations through scenario thinking activity.

Based on a script, the four future scenarios generated from the cross-impact matrix exercise were translated into more detailed policy orientated interpretations using a causal mapping technique to structure system constraints. As much of the information held by participants was judgemental, story-telling ${ }^{[7]}$ was encouraged to 
help shape how each scenario could unfold over time. Officers described events and examples of when actions had worked well in resolving incidents or conversely when situations had encountered systemic problems. This storytelling tactic suited the officers within the group who were familiar with this type of approach for eliciting tacit information from victims at critical interviews (Taylor, 2005).

As the participants described cause and effect in their own terms, the facilitator was able to sketch simple cause-effect maps ${ }^{[8]}$ to capture these relationships and categorise relevant information to reflect what had been learnt by the group through the narrative enquiry approach ${ }^{[9]}$ and represent the interaction of components for each policy scenario. The analysis of these interactions provided information about which DCP structures and controls may need adjusting to unfreeze the current state of the organisation before moving towards a specific visualised scenario policy option.

Figure 3 provides an example of a causal map component developed within the group. Arrows are used indicate cause-effect direction with the central theme labelled within the loop. In this example, four elements interact to provide a feedback loop to represent the process of promoting patrol officers to tenured roles. Achieving basic knowledge increases career path opportunities, which in turn increases promotion opportunities beyond patrol. This then reduces overall knowledge and skills retained within the patrol pool. The group confirmed that this feedback had a detrimental effect on providing RPO capability.

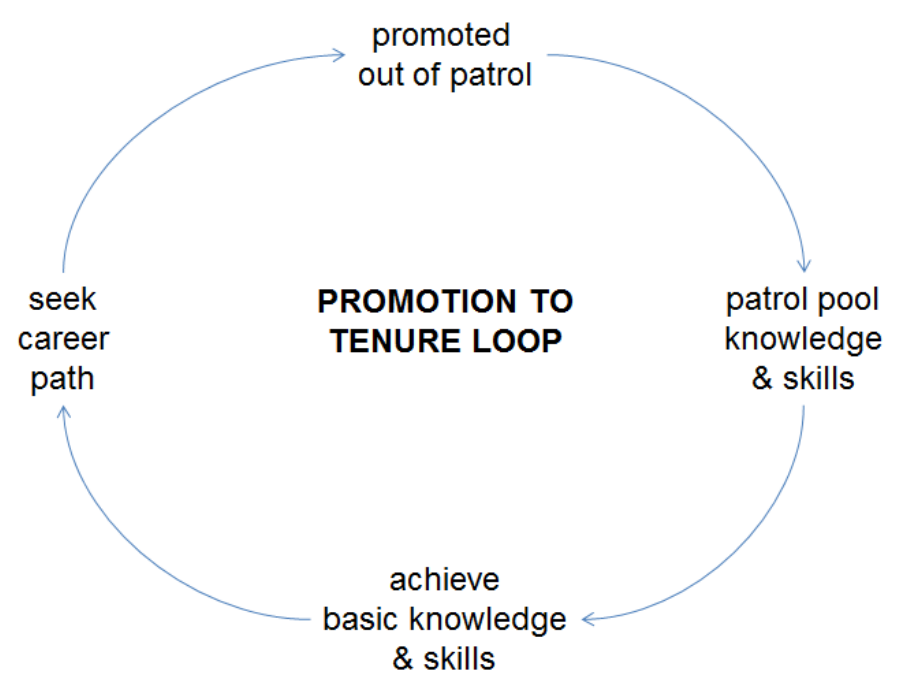

Figure 3. Example Causal Map

The following four scenarios were agreed by the group as possible policy pathways (as an evolution from the earlier viable futures): Business as Usual (No Change), Workforce Modernisation (More Resources), Operation QUEST (Less Demand and Fewer Resources), US Navy Home Port (Rotational Resource) as specified in Figure 1.

Business as Usual (i) - identify baseline position where no changes to resourcing the RPO is instituted, providing a referent trajectory for comparing other detailed scenarios. Maintain the target seeking controls to meet the total Devon and Cornwall Police (DCP) headcount of 3500 officers with the associated free-flow of 
officers from training to RPO then tenure. The existing cause-effect connections previously identified reflect this status quo system performance.

Workforce Modernisation (ii) - is a Home Office methodology that has been used in UK police forces to improve workforce skill utilisation by ensuring that highly competent officers are redeployed in numbers to meet the demands placed on the response patrol officer function. It was envisaged that up to 200 DCP officers could be redeployed en masse from tenured roles into the function with minimal impact on performance in other functions due to civilian replacement of vacated officer roles.

Operation QUEST ${ }^{\mathrm{TM}}$ (iii) - is a combined KPMG/Home Office methodology that can improve operational police processes through specialisation of work. DCP could consider transferring up to 46 RPOs to deal specifically with routine grade incidents, leaving the remaining RPO pool responding to immediate and prompt incidents.

Home Port (iv) - as yet untested in UK policing, Home Port refers to a US navy system where sailors are rotated between deployment at sea and shore based duties located at their home port. The group recognised that a similar approach could be adopted in DCP where officers are periodically moved between RPO and tenure to ensure that the skills of experienced officers are available to both functions (current policy favours tenure due to minimum tenure time to return on specialised role-related investments).

A set of qualified scenarios emerged from the Phase Two workshop. A common consensus on the structural constraints and policy barriers aligned to these alternative scenario options was achieved. This allowed next the development of a policy orientated system dynamics model to simulate the resourcing of the function.

\subsubsection{Phase Three: Integrating from now to alternative future(s)}

Equipped with details of what each future might entail, from causal maps and scenario plans, it was possible to develop a system dynamics simulation model with quantified starting values parameterised through GMB again, using a scripted process to facilitate this. This signified the final phase of resolving the supplydemand RPO resourcing issue through developing a simulation model. This would allow essential actions to be implemented in order to realise one or more of the four alternative (scenario) futures to best align longer term RPO resourcing outcomes to the DCP vision, mission and values. A fully parameterised and calibrated system dynamics model would offer DCP a clear choice between alternative RPO resourcing policy options that could construct a scientific theory between planned action and desired change currently lacking in less rigorous decision-making approaches.

In the final workshop of this GMB process, the aim was to sketch the stock-flow structure of the system dynamics model, add additional parameters and variables to that structure and then numerically calibrate the model to allow it to run as a simulation to test policy options.

The causal maps developed in the Phase Two workshop were translated by the group into stock-flow diagram ${ }^{[10]}$ to represent the supply of RPO and the incident demands placed on the function. Figure 4 summarises the key elements of the stock-flow diagram produced with the group (See Carter and Moizer, 2011 for full stock-flow diagram). The stock-flow demand for RPO assistance is characterised as a backlog of incidents awaiting resolution (stock) and being resolved by response- 
patrol officer function (flow). This flow rate is governed by the availability of experienced officers. The RPO capacity is constrained by the requirement for many officers in DCP to work in tenured roles as well as reduced capabilities of the officers still under training to deal effectively with the range of incidents they might encounter. The backlog of requests is represented as an array function to reflect incidents requiring attention based on priority of response The group confirmed that within DCP, police incidents are assigned one of three priorities: immediate, prompt or routine, and that available RPO resource is allocated in that order.

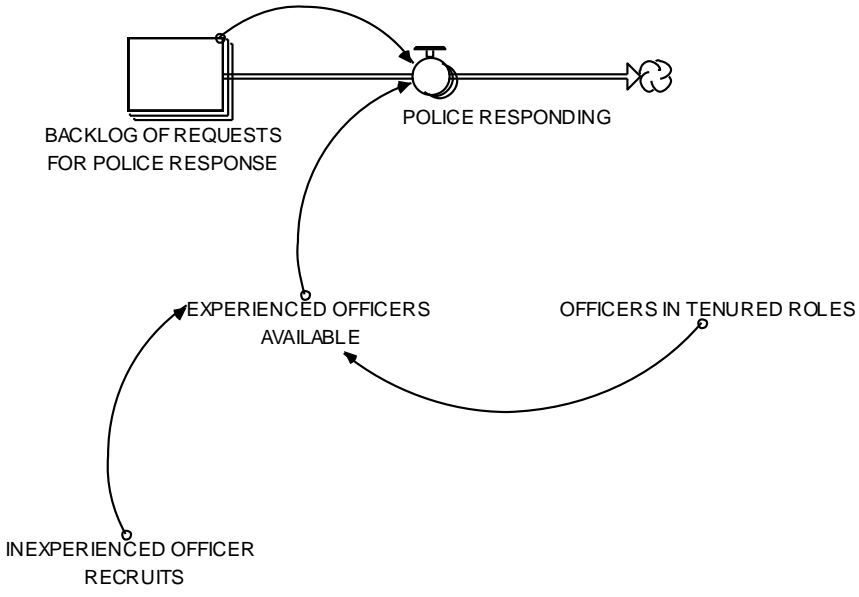

Figure 4. Stock-flow Representation of the RPO Assistance Process

Structural constraints and policy barriers were added to the baseline diagram for the Business as Usual (i) scenario, with minor adjustments to variables and parameters to accommodate the remaining three scenarios (ii) through to (iv).

Various sources of written, electronic and personal experience information were used to populate the stock flow diagram with equations and parameter values as a precursor to simulating each policy scenario. Where data was not available, specialised scripts were used with the group to elicit numerical values. The core RPO diagram was then translated off-line into a system dynamics model featuring parameters and equations elicited from this final workshop. This required a number of structure (structure-verification, parameter-verification, and extreme-conditions), behaviour (behaviour-prediction and behaviour sensitivity) and policy implication (changed-behaviour-prediction and boundary-adequacy) tests to be performed as part of the model validation and confidence building.

The fully quantified scenarios were simulated for each RPO resourcing policy option. Maintaining a Business as Usual (i) approach was quickly established as problematic, where RPO and experience shortages were shown to diminish the capacity to deal with lower grade incidents over time. Simulating the Workforce Modernisation (ii) policy (returning 200 full time equivalents - fte to the function) showed an increase in officer headcount in the short term without addressing the longer term outflow of officers to tenure, again resulting in a diminished capacity in the longer term. For Operation Quest (iii) the redeployment of officers (ring-fencing 46 fte by moving them away from RPO duties) resulting in a fifth fewer demands on the function. RPO capacity was shown to diminish at a quicker rate than with the Workforce Modernisation but the impact was less pronounced. Home Port (iv) was the last scenario considered where officers rotated between RPO and tenured roles. This simulation indicated that it was the most sustainable policy for maintaining the 
function's capacity, as experienced officers are periodically returned from tenure to patrol ensuring that adequate headcount and associated experience levels can be conserved within the function are available.

\section{Case Study Discussion and Implications}

This Devon and Cornwall Police (DCP) case study demonstrated how system dynamics models can be developed through expert group participation using a modelling multimethodology to help understand complex policy issues for policing services. Applying the multimethodology has generated valuable perspectives into the development of a policy orientated simulation model with potential adaption and application to other managerial problems.

\subsection{Using group model building to facilitate multimethodological modelling}

As a catalyst in this study, GMB offered the modellers descriptions of real-world issues at the same time as providing DCP participants with policy insights on previously unquantified relationships between complex interacting causal entities. Greater understanding between parties was generated through the cross-fertilisation of multiple method perspectives that helped everyone to negotiate the scope of the key system features and their dynamics. This provided essential confidence in the fidelity of this model building approach that can offer value to others making policy decisions on similarly messy issues. As Rouwette et al, (2009) assert, modelling and facilitation not only improves information processing within the group context, but supports the exchange of arguments through high quality communication.

\subsection{Benefits and limitations within the case study}

Benefits of the three phase methodology have included participatory qualitative verification and quantitative validation of this simulation model and its resulting scenario predictions of dynamic performance. Using several modelling methods to progress the DCP group understanding of alternative policy options allowed not only insight and understanding to be gained and communicated, but ownership of the emergent system dynamics model to be realised. The GMB also allowed participants to engage in critical investigation providing an antidote to the dangers of groupthink (Vennix, 1999).

A key limitation with the methodological approach relates to scaling the process across a larger group of contributors. Here the small group dynamic diminishes and the process naturally takes longer to conclude. In order to counter this scaling constraint, specialist groups deciding smaller areas of model detail might need to be combined by senior management taking a holistic view of the issue.

\subsection{Generating group perspectives through multimethodological modelling}

Applying the multimethodology led to a policy orientated system dynamics model of the RPO function, with elements of the model informed by the qualitative modelling phases, namely scenario planning followed by causal mapping. These earlier system perspectives were integrated into the simulation model where variables that 
may prima facia have appeared to have little impact on the policy outcomes. These could be represented and then tested to understand whether they can be ruled in or out of the dynamically messy issue. The range of individual 'pet theories' on how the RPO system operated could be challenged and assumptions modified through group consensus. The backend of the modelling process allowed the group to converge their thinking towards a set of shared numerical model parameters arrived at from different starting points based on individual mental models.

\subsection{Case study group model building value}

GMB can help to uncover and incorporate tacit information held by group members into a dynamic policing policy-orientated simulation model. System dynamics modelling can achieve this by enabling different combinations of structural and control mechanisms to be elicited from stakeholders and tested on key aspects of the system under consideration, i.e. the officer resource allocation mechanism. Figure 5 provides a view of the benefits encountered by DCP using GMB.

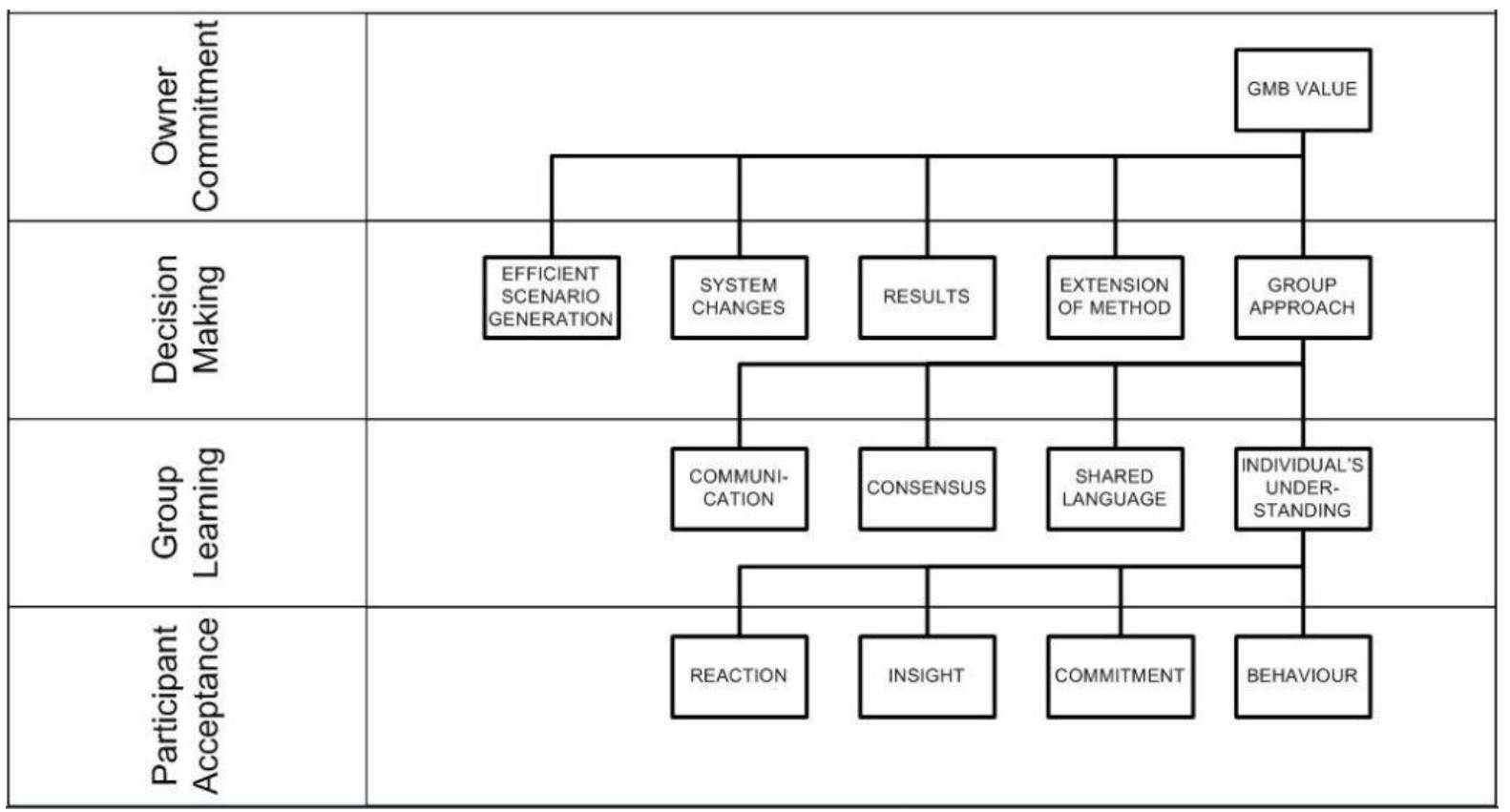

Figure 5. Multi-level GMB Benefits (adapted from Rouwette et al., 2002)

The structure comprises a vertical strata describing the organisational levels of DCP associated with the GMB process. In the top strata, Owner Commitment, issue owners represented by the Chief Officers were provided with scenario outcomes to support policy development based on simulating alternative response-patrol officer resource futures. In the second strata, Decision Making, GMB offers decision support to functional managers (mid-ranking officers and civilian staff) in the form of scenarios generated, simulated changes and their results. In addition, these managers also have an expert group (policing champions) within DCP that is capable of communicating rationales for and against particular courses of action that are tested through simulation. The system dynamics model results provide the insights to support particular courses of action to change the response-patrol resourcing policy. Given that GMB offers an efficient way to build a shared model capable of answering multiple queries about the system and its dynamic 
performance, there may be further opportunities to re-use the approach for understanding other DCP issues. Equally, once changes have been made to the RPO system, the model can track and predict future system performance in an ongoing way supporting synchronisation of policy implementation. Within the selected expert group, in the third strata, Group Learning, (front-line sergeants and inspectors plus equivalent civilian managers) the GMB approach offers a rational process for the development of shared language around the issue, group dialogue and debate which can move towards a consensus view of how resourcing issues are structured. Importantly, the group's participants move towards a shared understanding of the challenge which can be disseminated to others within DCP and beyond. Finally, in the fourth strata, Participant Acceptance, the benefits for individuals can comprise of their reaction to new information about the response-patrol officer (RPO) system, the insights they developed, their personal commitment to shared courses of action and the changes to their own practice within DCP. One potential development of the multimethodological approach would be to test this level of commitment at various points in the GMB engagement to better understand convergence phenomena.

\section{Conclusion of the Case Study Application}

The viable futures negotiated by the group (Phase One) and associated simulation boundaries informed the search for current barriers in the system (Phase Two) within which existing system constraints would be tested. It also enabled system dynamics structure to be assembled (Phase Three) in a way that accommodated the complex system interactions under consideration.

Through the mechanism of GMB, the final system dynamics model reflected the extent and nature of the RPO resourcing issue and policies to address it. The benefits of adopting a GMB approach to building consensus were realised by the organisation. Different perspectives provided by a multimethodology involving scenario planning, causal mapping and stock flow diagramming enabled clarity of purpose, process and available options to be determined for DCP. The system dynamics model allowed DCP to test policy options through the safety of a simulation before considering policy solutions for implementation. By adopting a simulated approach to resolving the messy issue of RPO resourcing, both cost-risks and time delays can be reduced.

Balancing the supply of police officers to the demands for frontline service to the public is generic to all police forces. Within the UK, successive policing reviews continue to seek resource efficiencies through superior policies. A three phase modelling process can assist policing policy makers in other jurisdictions to both understand interrelated issues and evaluate alternative courses of action given officer resource constraints. There are two limitations to this study; the first being the size of the modelling group which comprised of a restricted number of participants. The involvement of more participants could have helped to provide wider views of the issue under investigation in exchange for more time and resource. The second is the absence of a fourth GMB workshop for debriefing the group on the GMB process and simulated outputs. Debriefing the simulation model results did take place through wider DCP process improvement teams who commented on possible policy futures derived from the simulated outputs. 
This three phase methodological approach could be widened to other public sector organisations where it is evident that structural and dynamic complexity could be overwhelming for individual analytical approaches. The emergency services on land, air and sea can potentially benefit from multimethodological modelling of policy imperatives under conditions where demand is prioritised and resources are limited. They may additionally benefit from using a series of modelling methods to achieve robust policy evaluation. Public services could also find more cost-effective solutions through pre-testing strategic policy decisions, in isolation or combined together, using multimethodological modelling.

In conclusion, this case study has illustrated how a multimethodological modelling approach has allowed a UK police force to explore and explain their demand management issues and support thinking about resourcing policy for their future RPO function.

\section{References}

Ackermann, F. Andersen, D.F. Eden, C. and Richardson, G.P. (2010), "Using a group decision support system to add value to group model building", System Dynamics Review, Vol. 26 No. 4, pp. 335-346.

Ackermann, F. Andersen, D.F. Eden, C. and Richardson, G.P. (2011), "ScriptsMap: A tool for designing multi-method policy-making workshops", Omega, Vol. 39, pp. 427-434.

Ackermann, F. and Eden, C. (2011), "Negotiation in strategy making teams: group support systems and the process of cognitive change", Group Decision and Negotiation, Vol. 20, pp. 293-314.

Akkermans, H.A. and Vennix, J.A.M. (1997), "Clients' opinions on group model building: an exploratory study", System Dynamics Review, Vol. 13 No. 1, pp. 3-31.

Andersen D.F. and Richardson, G.P. (1997), "Scripts for group model building", System Dynamics Review, Vol. 13 No. 2, pp. 107-129.

Andersen D.F., Richardson, G.P. and Vennix, J.A.M. (1997), "Group model building: Adding more science to the craft", System Dynamics Review, Vol. 13 No. 2, pp. 187-201.

Bandini S., Petraglia F., Sartori F. (2009), "Social and Domain Knowledge Management through the Integration of Storytelling and Case Based Reasoning", in Sicilia M.A. and Lytras, M.D. (Eds.), Metadata and Semantics, Springer Verlag, pp. 365-374.

Barbosa, S.E. and Petty, M.D. (2014), "Exploiting spatio-temporal patterns using partial-state reinforcement learning in a synthetically augmented environment", Progress in Artificial Intelligence, DOI 10.1007/s13748-0140057-2.

Barton, L.C. and Barton, H. (2011). "Challenges, issues and change: what's the future for UK policing in the twenty first century?", International Journal of Public Sector Management, Vol. 24 No. 2, pp. 146-156. 
Bérard, C. (2010), "Group model building using system dynamics: an analysis of methodological frameworks", Electronic Journal of Business Research Methods, Vol. 8 No. 1, pp. 187-201.

Bérard, C., Cloutier, L.M. and Cassivi, L. (2011), "Evaluating clinical trial management systems: a simulation approach", Industrial Management \& Data Systems, Vol. 112 No. 1, pp. 146-164.

Brooks, J.P., Edwards, D.J., Sorrell, T.P., Srinivasan, S. and Diehl, R.L. (2011), "Simulating calls for service for an urban police department", Proceedings of the 2011 Winter Simulation Conference in Phoenix, AZ, USA, December 11 14, 2011. pp. 1770-1777.

Brown, J., Cooper, C. and Pidd, M. (2006), "A taxing problem: The complementary use of hard and soft OR in the public sector", European Journal of Operational Research, Vol. 172, pp. 666-679.

Cairns, G., Wright, G, van der Heijden, K., Bradfield, R. and Burt, G. (2006), "Enhancing foresight between multiple agencies: Issues in the use of scenario thinking to overcome fragmentation", Futures, Vol. 38, pp. 1010-1025.

Carter, D. and Moizer, J.D. (2011), "Simulating the impact of policy on patrol policing: introducing the emergency service incident model", System Dynamics Review, Vol. 27 No. 4, pp. 331-357.

Château, P.A., Chang, Y.C., Chen, H. and Ko, T.T. (2012), "Building a stakeholder's vision of an offshore wind-farm project: A group modelling approach", Science of the Total Environment, Vol. 420, pp. 43-53.

Curtin, K.M., Hayslett-McCall, K. and Qui, F. (2010), "Determining optimal police patrol areas with maximal covering and backup covering location models", Networks and Spatial Economics, Vol. 10, pp. 125-145.

Eden, C. and Ackermann, F. (1998), Making Strategy: The Journey of Strategic Management, Sage, London.

Eden, C. and Ackermann, F. (2004), "Cognitive mapping expert views for policy analysis in the public sector", European Journal of Operational Research, Vol. 152 , pp. $615-630$.

Ferreira, J.S. (2012), "Multimethodology in metaheuristics", Journal of the Operational Research Society, Vol. 64 No. 6, pp. 873-883.

Forrester, J.W. (1961), Industrial Dynamics, Productivity Press, Portland, OR.

Franco, L.A., Montibeller, G. (2010), "Facilitated modelling in operational research", European Journal of Operational Research, Vol. 205 No. 3, pp. 489-500.

Ghaffarzadegan, N., Lyneis, J. and Richardson, G.P. (2011), "How small system dynamics models can help the public policy process", System Dynamics Review, Vol. 27 No. 1, pp. 22-44.

Gil-Garcia, J.R. and Pardo, T.A. (2006), "Multi method approaches to understanding the complexity of E-government", International Journal of Computers, Systems and Signals, Vol. 7 No. 2, pp. 3-15.

Hoppenbrouwers, S. and Rouwette, E. (2012), "A dialogue game for analysing group model building: Framing collaborative modelling and its facilitation", 
International Journal of Organisational Design and Engineering, Vol. 2 No. 1, pp. 19-40.

Howick, S and Ackermann, F. (2011), "Mixing OR methods: Past, present and future directions", European Journal of Operational Research, Vol. 215, pp. 503-511.

Howick, S. and Eden, C. (2011). "Supporting strategic conversations: The significance of the model building process", Journal of the Operational Research Society, Vol. 62 No. 5, pp. 868-878.

Ip, W.H., Chan, S.L. and Lam, C.Y. (2011), "Modeling supply chain performance and stability", Industrial Management \& Data Systems, Vol. 111 No. 8, pp. 13321354.

Jovanoski, B., Minovski, R.N., Lichtenegger, G. and Voessner, S. (2013), "Managing strategy and production through hybrid simulation", Industrial Management \& Data Systems, Vol. 113 No. 8, pp. 1110-1132.

Kothari, A., Rudman, D., Dobbins, M., Rouse, M., Sibbald, S. and Edwards, N. (2012), "The use of tacit and explicit knowledge in public health: a qualitative study", Implementation Science Vol. 7, pp. 20-31.

Kotiadis, K. and Mingers, J. (2006), "Combining PSMs with hard OR methods: the philosophical and practical challenges", Journal of the Operational Research Society, Vol. 57, pp. 856-867.

Li, L., Jiang, Z., Duan, N. and Dong, W. (2011), "Police patrol service optimization based on the spatial pattern of hotspots", Proceedings of the Service Operations, Logistics, and Informatics (SOLI) 2011 IEEE International Conference, Beijing, China, July 10-12, 2011, pp 45-50.

Lindgren, M. and Bandhold, H. (2003), Scenario Planning The Link Between Future and Strategy, Palgrave MacMillan, London.

Luna-Reyes L.F., Martinez-Moyano, I.J., Pardo, T.A., Cresswell, A.M., Andersen, D.F. and Richardson, G.P. (2006), "Anatomy of a group model building intervention: building dynamic theory from case study research", System Dynamics Review, Vol. 22 No. 4, pp. 91-320.

Luna-Reyes, L.F., Mojtahedzadeh, M., Andersen, D.F., Richardson, G.P., Pardo, T. and Burke, B. (2004), "Scripts for interrupted group model building: Lessons from modeling the emergence of government structures for information integration across Government Agencies", Proceedings of the $22^{\text {nd }}$ International System Dynamics Conference, Oxford, UK, July 25-29, 2004.

Luna-Reyes, L.F. and Andersen, DF. (2003), "Collecting and analysing qualitative data for system dynamics: Methods and models", System Dynamics Review, Vol. 19 No. 4, pp. 271-296.

Mingers J. (2000), "Variety is the spice of life: combining soft and hard OR/MSmethods", International Transactions in Operational Research, Vol. 7 , pp. 673-691.

Mingers, J. and Brocklesby, J (1997), "Multimethodology: Towards a framework for mixing methods", Omega, Vol. 25 No. 5, pp. 489-509. 
Munro, I and Mingers, J. (2002), "The use of multimethodology in practice - Results of a survey of practitioners", Journal of Operational Research Society, Vol. 53, pp. 369-378.

Neufeld, N.J., Hoyer, E.H., Cabahug, P., González-Fernández, M., Mehta, M., Walker, N.C., Powers, R.L. and Mayer, R.S. (2013), "A lean six sigma quality improvement project to increase discharge paperwork completeness for admission to a comprehensive integrated inpatient rehabilitation program", American Journal of Medical Quality, Vol. 28 No. 1, pp. 40-45.

Newsome, I.M. (2008), "Using system dynamics to model the impact of policing activity on performance", Journal of the Operational Research Society, Vol. 59, pp. 164-170.

Peterson, G.D., Cuming, G.S. and Carpenter, S.R. (2003), "Scenario planning: A tool for conversation in an uncertain world", Conservation Biology, Vol. 17 No. 2, pp. 358-366.

Richardson, G.P. and Andersen, D.F. (1995), "Teamwork in group model building", System Dynamics Review, Vol. 11 No. 2, pp.113-137.

Rouwette, E.A.J.A. (2011), "Facilitated modelling in strategy development: measuring the impact on communication, consensus and commitment", Journal of the Operational Research Society, Vol. 62, pp. 879-887.

Rouwette, E.A.J.A., Vennix, J.A.M. and van Mullenkom, T.(2002), "Group model building effectiveness; a review of assessment studies", System Dynamics Review, Vol. 18 No.1, pp. 5-45.

Rouwette E.A.J.A., Vennix, J.A.M, and Felling A.J.A. (2009), "On evaluating the performance of problem structuring methods: an attempt at formulating a conceptual model", Group Decision and Negotiation, Vol. 18, pp. 567-587.

Rouwette E.A.J.A., Korzilius, H. Vennix, J.A.M. and Jacobs, E. (2011), "Modeling as persuasion: The impact of group model building on attitudes and behaviour", System Dynamics Review, Vol. 27 No. 1, pp. 1-21.

Santos, S. Belton, V., and Howick, S. (2008), "Enhanced performance measurement using OR: A case study", Journal of the Operational Research Society, Vol. 59, pp. 762-775.

Srinivasan, S., Sorrell, T.P., Brooks, J., Edwards, D.J., McDougie, R.D. (2013), "Workforce assessment method for an urban police department: Using analytics to estimate patrol staffing", Policing: An International Journal of Police Strategies and Management, Vol. 36 No. 4, pp. 702-718.

Sterman J. (2001), "System dynamics modeling; tools for learning in a complex world", California Management Review, Vol. 43, pp. 8-25.

Stave, K.A. (2002), "Using system dynamics to improve public participation in environmental decisions", System Dynamics Review, Vol. 18, pp.139-167.

Stewart, TJ. French, S. and Rios, J. (2013), "Integrating multicriteria decision analysis and scenario planning - review and extension", Omega, Vol. 41 No. 4, pp. 679-688. 
Taylor, H. (2005), A critical decision interview approach to capturing tacit knowledge: Principles and application", International Journal of Knowledge Management, Vol. 1 No. 3, pp. 25-39.

Trochim, W.M., Cabrera, D.A., Milstein, B., Gallagher, R.S. and Leischow, S.J. (2006), "Practical Challenges of Systems Thinking and Modeling in Public Health", American Journal of Public Health, Vol. 96 No. 3, pp. 538-546.

van der Heijden, K. (2005), Scenarios, The Art of Strategic Conversation, 2nd edition, Wiley, Chichester, UK.

Vennix, J.A.M. (1995), "Building consensus in strategic decision making: system dynamics as a group support system", Group Decision and Negotiation, Vol.4, pp. 335-355.

Vennix, J.A.M. (1996), Group Model Building: Facilitating Team Learning Using System Dynamics. Wiley, Chichester, UK.

Vennix, J. (1999), "Group model-building: Tackling messy problems", System Dynamics Review, Vol.15 No. 4, pp. 379-401.

Wang, B. and Moon, Y.B. (2012), "Hybrid modelling and simulation for innovation deployment strategies", Industrial Management \& Data Systems, Vol. 113 No. 1, pp. 136-154.

Zhang, Y. and Brown, D.E. (2013), "Police patrol districting method and simulation evaluation using agent-based models \& GIS", Security Informatics, Vol.2 No. 7, pp. 1-13.

\footnotetext{
${ }^{1}$ A government department responsible for policing, immigration, drugs policy and counter-terrorism.

[2] Journey Making is a development of the Strategic Options and Development Analysis technique which has helped with the development of group decision support systems (Eden and Ackermann, 1998; Ackermann and Eden, 2011).

${ }^{[3]}$ Grey-box as distinct from black-box where model structure is opaque to the client or observer.

${ }^{[4]}$ Tenured officers work in roles outside of the response-patrol officer function that require specific training investment.

${ }^{[5]}$ PESTEL is a framework to identify external drivers of change in strategic environments and stands for political, economic, social, technological, environmental and legal categories.

${ }^{[6]}$ A scenario describes a possible future situation that may or may not materialise. They can be characterised as structured dynamic stories that capture key elements of uncertainty about how possible futures may evolve (Peterson et al, 2003). Scenario planning is an approach that gathers the richer picture surrounding the issue being studied and allows alternative futures to be preexperienced (van der Heijden, 2005). Groups can be used to generate realistic futures by taking into account wider perspectives of the system to understand the nature and scope of the issue being tackled. Groups discussions about viable scenarios extend beyond the formal scenario planning process and can be described as scenario thinking (Stewart et al, 2013) which acts as an enabling mechanism for strategic conversations (Cairns et al, 2006).

${ }^{[7]}$ Storytelling is a narrative approach where individuals explain an experience within a specific theme. Their narrative is focused on explaining tacitly held knowledge concerning the issue being described. Storytelling can bring meaning and structure to the event being told with benefits to those who tell and those who listen (Bandini et al, 2009).

${ }^{[8]}$ Causal mapping (or cognitive mapping) can be used to specify cause and effect between system elements using arrows to indicate causal direction (see Eden and Ackermann, 2004; Neufeld et al, 2013 for fuller outlines of the technique).

${ }^{[9]}$ See (Kothari et al 2012) for a detailed outline of how causal maps can be used as a means of eliciting tacit knowledge through focus on action and skills to link experiences to events.
} 
${ }^{[10]}$ Stocks-flow diagrams use system dynamics notation and represent key accumulations or stocks and their inflows and outflows. Stocks are dynamic in that their accumulations vary over time according to flow adjustments. 